\title{
Intravenous thrombolysis outcome in posterior vs anterior circulation stroke in a tertiary stroke center in Egypt
}

\author{
Nourhan Abdelmohsen Taha* (D), Hala El Khawas, Mohamed Amir Tork and Tamer M. Roushdy
}

\begin{abstract}
Background: Intravenous thrombolysis (IVT) with alteplase is the first-line therapy for acute ischemic anterior and posterior circulation strokes (ACS and PCS).

Knowledge about safety and efficacy of IVT in posterior circulation stroke is deficient as most of the Egyptian studies either assessed IVT outcome in comparison to conservative therapy or its outcome in anterior circulation stroke only.

Therefore, our aim was to compare the relative frequency and outcome after intravenous thrombolysis in anterior versus posterior circulation stroke patients presenting to stroke centers of Ain Shams University hospitals (ASUH).

Results: A total of 238 anterior circulation stroke and 61 posterior circulation strokes were enrolled, onset-to-door and door-to-needle time were statistically insignificant.

NIHSS showed comparable difference at all time points despite higher scores along anterior circulation stroke; 90day modified Rankin Scale (mRS) showed significant improvement in both groups from mRS $>2$ to $\leq 2$ with a better percentage along posterior circulation stroke patients.

There was insignificant difference for either incidence of death or intracranial hemorrhage (ICH) between the two groups.

Conclusion: IVT significantly reduced NIHSS for both anterior and posterior circulation stroke along different studied time points. Meanwhile, a higher percentage of patients with posterior circulation stroke had a better mRS outcome at 90 days.
\end{abstract}

Keywords: Thrombolysis, Stroke center, Posterior circulation stroke, Outcome, Egypt

\section{Background}

Intravenous thrombolysis (IVT) with alteplase is still the first-line therapy for all kinds of acute ischemic stroke (AIS) including both the anterior circulation stroke (ACS) and posterior circulation stroke (PCS) [1].

The IVT concept emerged after all the trials aiming at saving the brain tissue began in 1995; National Institute of Neurological Disorders and Stroke (NINDS) introduced the use of recombinant tissue-type plasminogen activator (r-tPA) (Alteplase) for the first time after its 2-

\footnotetext{
* Correspondence: nourhan.attiah@med.asu.edu.eg

Neurology Department, Faculty of Medicine, Ain Shams University, 38 Abbasia, PO 11591, Cairo, Egypt
}

\section{Springer Open}

phase randomized controlled trial "Tissue Plasminogen Activator for Acute Ischemic Stroke", which proved that the use of alteplase improved the clinical outcome of the patients when compared to placebo [2].

It has been assumed that PCS has worse outcome in comparison to ACS; this has been always correlated to that the severity of ACS leads to seeking help earlier, so ACS patients receive treatment faster resulting in improved outcome. Moreover it was always assumed that the prognosis of the PCS is worse than ACS with higher mortality and morbidity rates [3].

Despite these assumed differences, the knowledge concerning the safety and efficacy of IVT in PCS is sparse

(c) The Author(s). 2021 Open Access This article is licensed under a Creative Commons Attribution 4.0 International License, which permits use, sharing, adaptation, distribution and reproduction in any medium or format, as long as you give appropriate credit to the original author(s) and the source, provide a link to the Creative Commons licence, and indicate if changes were made. The images or other third party material in this article are included in the article's Creative Commons licence, unless indicated otherwise in a credit line to the material. If material is not included in the article's Creative Commons licence and your intended use is not permitted by statutory regulation or exceeds the permitted use, you will need to obtain permission directly from the copyright holder. To view a copy of this licence, visit http://creativecommons.org/licenses/by/4.0/. 
due to various causes as lack of randomized controlled trials or phase IV studies that were concerned with the safety and efficacy of IVT according to type of circulation affected, starting from NINDS to ATLANTIS study, so further studies are needed to assess the efficacy of IVT in PCS [2-6].

To our knowledge studies done in Egypt assessing IVT outcome according to affected arterial territory are limited. Most of such studies either assessed IVT outcome in comparison to conservative treatment or assessed IVT outcome in ACS only [7, 8].

In this study, we aimed to assess relative frequency and outcome after IVT in both ACS and PCS patients presenting to stroke centers of Ain Shams University hospitals.

\section{Methods}

After receiving an ethical approval from Ain Shams University Ethical committee, this prospective cohort study was conducted along a period from February 2016 till May 2019 on acute ischemic stroke patients who presented to the stroke centers of Ain Shams University hospitals and were eligible to receive $r$-tPA.

Patients were enrolled after a formal written consent and were subjected to a full neurological assessment including history and examination.

The cases enrolled were those with clinical presentation of acute ischemic cerebrovascular stroke, within 4.5 $\mathrm{h}$ from stroke onset, excluding those who were not eligible for IVT, those with history of recurrent cerebrovascular insult, patients whom underwent endovascular thrombectomy, and those injected depending on radiological mismatch.

National Institute of Heath Stroke Scale (NIHSS) was performed at four time points, pre r-tPA, then $2 \mathrm{~h}, 24 \mathrm{~h}$, and 7 days post r-tPA, while modified Rankin Scale (mRS) was assessed at discharge and after 90 days.

The collected data was revised, coded, tabulated, and introduced to a personal computer (PC) using Statistical package for Social Science (SPSS) version 20. Data was presented and suitable analysis was done according to the type of data obtained for each parameter.

As regards descriptive statistics, mean, standard deviation $( \pm \mathrm{SD})$, and range for parametric numerical data was used, while median and interquartile range (IQR) were used for non-parametric numerical data. Moreover, frequency and percentage were used for non-numerical data.

As for analytical statistics, Student's $T$ test was used to assess the statistical significance of the difference between two study group means, repeated measure ANOVA test was used to assess the statistical significance of the difference between repeated measurements of the same variable, chi-square test was used to examine the relationship between two qualitative variables, Fisher's exact test was used to examine the relationship between two qualitative variables when the expected count was less than 5 in more than $20 \%$ of cells, and McNemar test was used to assess the statistical significance of the difference between a qualitative variable measured twice for the same study group.

$\mathrm{p}$ value $<0.05$ was considered significant.

\section{Results}

Along the studied period, a total of 432 patients with acute ischemic strokes were admitted to the stroke centers of Ain Shams University hospital (ASUH) and Ain Shams University specialized hospital (ASUSH).

After applying exclusion criteria, a total of 351 cases were eligible for r-tPA (290 were anterior circulation strokes and 61 were posterior circulation strokes), on 3month follow-up 65 cases dropped out (Fig. 1).

On assessing modifiable as well as non-modifiable vascular risk factors, there was no significant difference between the two studied groups (Table 1).

Upon comparing the two study groups (total 286 cases; divided into ACS 238 cases and PCS 48 cases), the mean onset-to-door (OTD) was $2.1 \mathrm{~h}$ with $\mathrm{SD} \pm 0.8$ for ACS and \pm 0.7 for PCS and the mean door-to-needle (DTN) was 50.6 min with SD \pm 22.3 for ACS and 45.6 min with SD \pm 19.9 for PCS, with non-significant difference ( $\mathrm{p}$ value was 0.9 and 0.1 respectively) (Table 2).

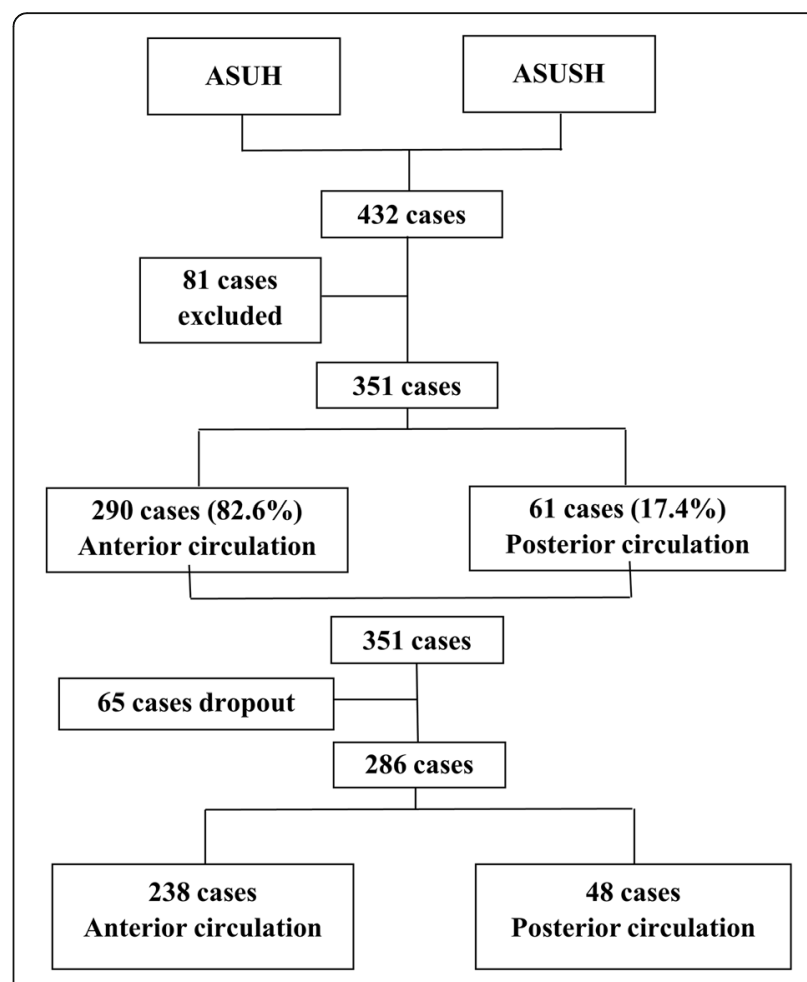

Fig. 1 The process of cases enrolment 
Table 1 Comparison of the distribution of risk factors among the two study groups and assessment of its significance

\begin{tabular}{|c|c|c|c|c|c|c|}
\hline \multirow[t]{3}{*}{ Risk factor } & & \multicolumn{4}{|l|}{ Site } & \multirow{3}{*}{$\begin{array}{l}\mathrm{T} \text { test } \\
\mathrm{p} \text { value }\end{array}$} \\
\hline & & \multicolumn{2}{|c|}{ Anterior Circulation Stroke } & \multicolumn{2}{|c|}{ Posterior Circulation Stroke } & \\
\hline & & Mean & SD & Mean & SD & \\
\hline \multirow[t]{2}{*}{ Age } & & 62.4 & 11.4 & 64.7 & 10.8 & 0.136 \\
\hline & & Number & $\%$ & Number & $\%$ & Chi-square test \\
\hline \multirow[t]{2}{*}{ Dyslipidemia } & No & 270 & $93.1 \%$ & 57 & $93.4 \%$ & 1 \\
\hline & Yes & 20 & $6.9 \%$ & 4 & $6.6 \%$ & \\
\hline \multirow[t]{2}{*}{$\mathrm{CHF}$} & No & 280 & $96.6 \%$ & 59 & $96.7 \%$ & 1 \\
\hline & Yes & 10 & $3.4 \%$ & 2 & $3.3 \%$ & \\
\hline \multirow[t]{2}{*}{ Gender } & Male & 179 & $61.7 \%$ & 40 & $65.6 \%$ & 0.573 \\
\hline & Female & 111 & $38.3 \%$ & 21 & $34.4 \%$ & \\
\hline \multirow[t]{2}{*}{ Smoking } & No & 235 & $81.0 \%$ & 48 & $78.7 \%$ & 0.673 \\
\hline & Yes & 55 & $19.0 \%$ & 13 & $21.3 \%$ & \\
\hline \multirow[t]{2}{*}{$\mathrm{AF}$} & No & 251 & $86.6 \%$ & 51 & $83.6 \%$ & 0.546 \\
\hline & Yes & 39 & $13.4 \%$ & 10 & $16.4 \%$ & \\
\hline \multirow[t]{2}{*}{ HTN } & No & 109 & $37.6 \%$ & 17 & $27.9 \%$ & 0.150 \\
\hline & Yes & 181 & $62.4 \%$ & 44 & $72.1 \%$ & \\
\hline \multirow[t]{2}{*}{ DM } & No & 185 & $63.8 \%$ & 36 & $59.0 \%$ & 0.483 \\
\hline & Yes & 105 & $36.2 \%$ & 25 & $41.0 \%$ & \\
\hline \multirow[t]{2}{*}{ Vascular disease } & No & 238 & $82.1 \%$ & 50 & $82.0 \%$ & 0.985 \\
\hline & Yes & 52 & $17.9 \%$ & 11 & $18.0 \%$ & \\
\hline
\end{tabular}

$S D$ standard deviation

Table 2 Comparison of the distribution of OTD and DTN, NIHSS at different time points, intracranial hemorrhage and death and their significance between the two study groups

\begin{tabular}{|c|c|c|c|c|c|}
\hline & \multicolumn{4}{|l|}{ Site } & \multirow{3}{*}{$\begin{array}{l}t \text { test } \\
p \text { value }\end{array}$} \\
\hline & \multicolumn{2}{|c|}{ Anterior circulation stroke } & \multicolumn{2}{|c|}{ Posterior circulation stroke } & \\
\hline & Mean & SD & Mean & SD & \\
\hline OTD (hour) & 2.1 & 0.8 & 2.1 & 0.7 & 0.9 \\
\hline DTN (min) & 50.6 & 22.3 & 45.6 & 19.9 & 0.1 \\
\hline NIHSS Pre r-tPA & 10.5 & 4.6 & 7.7 & 4.4 & $<0.001^{*}$ \\
\hline NIHSS $2 \mathrm{~h}$ & 8.8 & 4.9 & 6.1 & 4.2 & $<0.001^{*}$ \\
\hline NIHSS 24 h & 7.7 & 5.0 & 5.2 & 4.0 & $<0.001^{*}$ \\
\hline NIHSS 7 days & 6.4 & 4.8 & 4.3 & 3.9 & $0.001^{*}$ \\
\hline \multirow[t]{2}{*}{ Repeated measure ANOVA } & \multicolumn{2}{|l|}{$<0.001^{*}$} & \multicolumn{2}{|l|}{$<0.001^{*}$} & \\
\hline & \multicolumn{2}{|l|}{ Anterior } & \multicolumn{2}{|l|}{ Posterior } & \multirow{2}{*}{$\begin{array}{l}\text { Chi-square test } \\
\text { p value }\end{array}$} \\
\hline $\mathrm{ICH}$ & $\mathbf{N}$ & $\%$ & $\mathbf{N}$ & $\%$ & \\
\hline No & 97 & $82.2 \%$ & 17 & $85.0 \%$ & \multirow[t]{2}{*}{0.76} \\
\hline Yes & 21 & $17.8 \%$ & 3 & $15.0 \%$ & \\
\hline Death & & & & & $\begin{array}{l}\text { Fisher exact test } \\
\mathrm{p} \text { value }\end{array}$ \\
\hline No & 283 & $97.60 \%$ & 61 & $100.00 \%$ & 0.61 \\
\hline Yes & 7 & $2.40 \%$ & 0 & $0.00 \%$ & \\
\hline
\end{tabular}

*Significant

OTD onset-to-door, DTN door-to-needle, SD standard deviation, MIN minute, NIHSS National Institute of Health Stroke Scale, ICH intracranial hemorrhage 
The assessed NIHSS between the two studied groups at each time point (pre, $2 \mathrm{~h}$ post, $24 \mathrm{~h}$, and 7 days) showed significant improvement for both types of stroke despite higher scores was detected at baseline for ACS compared to PCS ( $\mathrm{p}$ value $<0.001$ at each time point) (Fig. 2).

Among the whole study group (286 cases), 212 cases had $\mathrm{mRS} \leq 2$ after 3 months $(74.1 \%)$ while 74 cases had mRS $>2$ after 3 months (25.9\%), of which 7 cases had $\mathrm{mRS}=6$ (death).

Upon comparing the two groups, 167 out of 238 ACS cases $(70.2 \%)$ and 45 out of 48 PCS cases (93.8\%) had $\mathrm{mRS} \leq 2$, while 71 ACS cases (29.8\%) and 3 PCS cases (6.3\%) had mRS $>2$ (Fig. 3), with the 7 death cases $(\mathrm{mRS}=6)$ lying within the anterior group, this difference in the outcome was found to be of highly significant difference ( $\mathrm{p}$ value $=0.001$ ), but it was non-significant as regards the difference among incidence of death of the cases $(\mathrm{p}$ value $=0.61)($ Table 2$)$.

Furthermore, upon assessing and comparing the mRS on discharge and 90 days, it was found that there was highly significant improvement in both anterior and posterior group, as of the 97 and 12 cases with mRS $>2$ on discharge 34 and 10 cases improved to $\leq 2$, with ACS showing higher significant improvement as regards the functional outcome compared to PCS with p value < 0.001 and 0.012 respectively (Table 3).

As regards the incidence of post t-PA intracranial hemorrhage, upon reviewing the post $24 \mathrm{~h}$ imaging, of

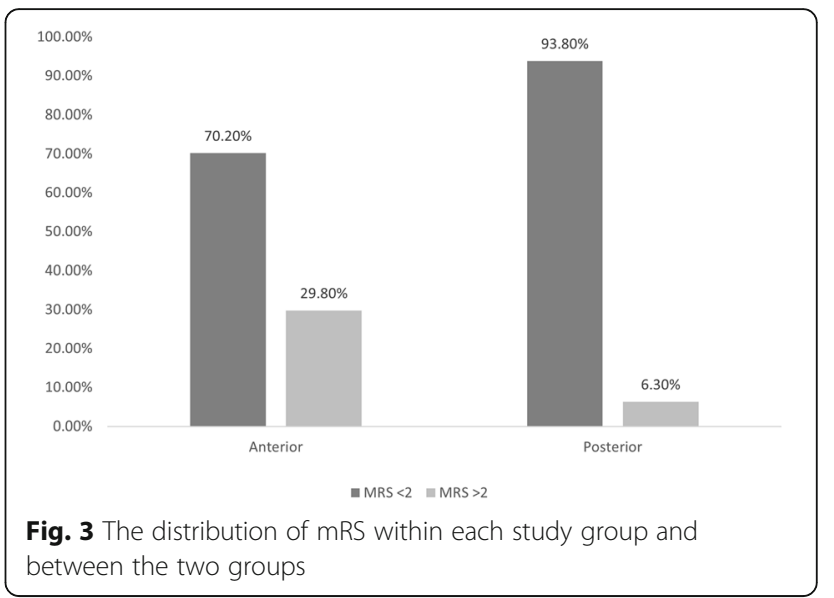

the total cases involved, 75 cases could not be reviewed due to lack of follow-up imaging in the registries; 24 cases (11.3 \%) showed evidence of intracranial hemorrhage, of these 21 belonged to ACS group in comparison to only 3 cases in PCS group, but this difference was statistically non-significant among the two groups (Table 2).

\section{Discussion}

In our study, we assessed the relative frequency and outcome according to serial NIHSS (pre t-PA, 2 h post, 24 $\mathrm{h}$ and 7 days), $\mathrm{mRS}$ at discharge and 90 days, and incidence of intracranial hemorrhage for the cases receiving

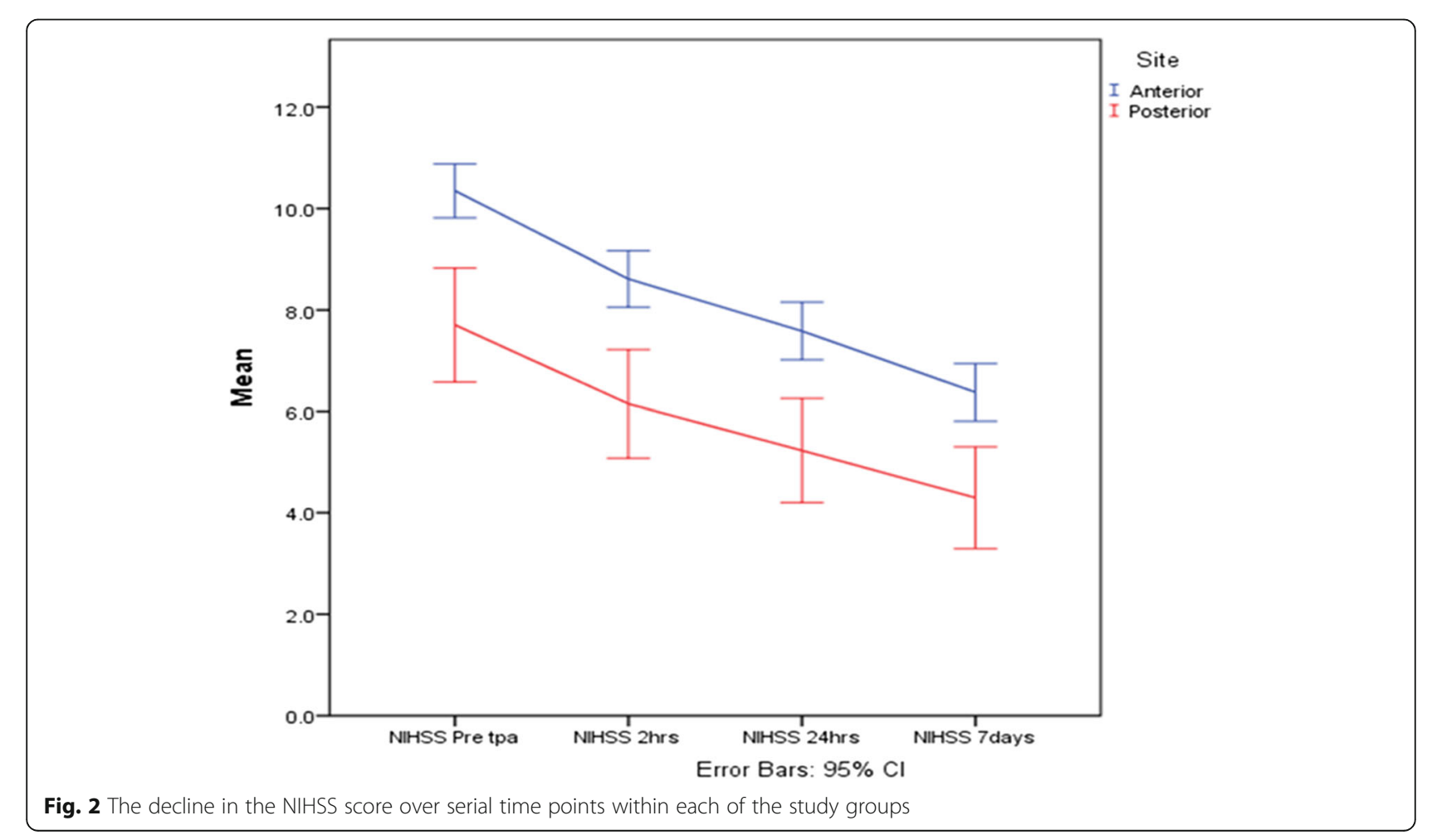


Table 3 Distribution of the mRS within all study cases, comparison of mRS at discharge and 3 months

\begin{tabular}{|c|c|c|c|c|c|c|c|}
\hline \multicolumn{3}{|c|}{ Modified Rankin score } & \multicolumn{4}{|c|}{ Number of cases } & \multirow{2}{*}{$\begin{array}{l}\text { Percentage (\%) } \\
74.1 \%\end{array}$} \\
\hline \multirow[t]{5}{*}{$\mathrm{mRS}$ at 3 months } & & $\leq 2$ & 212 & & & & \\
\hline & & $>2$ & 74 & & & & $25.9 \%$ \\
\hline & & & Site & & & & \multirow{3}{*}{$\begin{array}{l}\text { Chi-square test } \\
\mathrm{P} \text { value }\end{array}$} \\
\hline & & & ACS & & PCS & & \\
\hline & & & $\mathbf{N}$ & $\%$ & $\mathbf{N}$ & $\%$ & \\
\hline \multirow{2}{*}{\multicolumn{2}{|c|}{$\mathrm{mRS}$ at 3 months }} & $\leq 2$ & 167 & $70.20 \%$ & 45 & $93.80 \%$ & \multirow[t]{2}{*}{$0.001^{*}$} \\
\hline & & $>2$ & 71 & $29.80 \%$ & 3 & $6.30 \%$ & \\
\hline \multirow{2}{*}{\multicolumn{2}{|c|}{ Anterior }} & \multicolumn{3}{|l|}{$\mathrm{mRS}$ at $3 \mathrm{~m}$} & Total & & \multirow{2}{*}{$\begin{array}{l}\text { McNemar test } \\
\text { P value }\end{array}$} \\
\hline & & $\leq \mathbf{2}$ & & $>2$ & & & \\
\hline \multirow[t]{2}{*}{$\mathrm{mRS}$ at discharge } & $\leq 2$ & $133(55.88 \%)$ & & $8(3.36 \%)$ & $144(59.24 \%)$ & & \multirow[t]{2}{*}{$<0.001^{*}$} \\
\hline & $>2$ & $34(14.29 \%)$ & & $63(26.47 \%)$ & 97 (40.76\%) & & \\
\hline \multicolumn{2}{|l|}{ Total } & \multicolumn{2}{|l|}{$167(70.17 \%)$} & $71(29.83 \%)$ & \multicolumn{2}{|l|}{$238(100 \%)$} & \\
\hline \multirow{2}{*}{\multicolumn{2}{|c|}{ Posterior }} & \multicolumn{5}{|l|}{$\mathrm{mRS}$ at $3 \mathrm{~m}$} & \\
\hline & & $\leq 2$ & & $>2$ & & & \\
\hline \multirow[t]{2}{*}{$\mathrm{mRS}$ at discharge } & $\leq 2$ & 35 (72.92\%) & & $1(2.08 \%)$ & \multicolumn{2}{|l|}{$36(75 \%)$} & \multirow[t]{2}{*}{$0.012^{*}$} \\
\hline & $>2$ & $10(20.83 \%)$ & & $2(4.17 \%)$ & $12(25 \%)$ & & \\
\hline \multicolumn{2}{|l|}{ Total } & \multicolumn{2}{|l|}{45 (93.75\%) } & $3(6.25 \%)$ & \multicolumn{2}{|l|}{48 (100\%) } & \\
\hline
\end{tabular}

*Significant

mRS modified Rankin Score, ACS anterior circulation stroke, PCS posterior circulation stroke

alteplase and comparison was made according to the cerebral circulation affected, whether anterior or posterior.

Our study revealed that the relative frequency of ACS cases was 290 out of 351 cases (82.6\%) compared to 61 cases $(17.6 \%)$ for PCS; this matches the worldwide distribution for the relative frequency of type of cerebrovascular circulation affected, as well as multiple studies that were comparative in nature with posterior circulation prevalence ranging from 15 to $20 \%$ [9-11].

Moreover, the functional outcome of the cases at discharge and 90 days was found to be better in PCS compared to ACS; $75.17 \%$ and $93.75 \%$ in PCS had $\mathrm{mRS} \leq 2$ in comparison to ACS that showed only $59.24 \%$ and $70 \%$ of the cases with $\mathrm{mRS} \leq 2$ respectively; this agrees with a systematic review performed on other retrospective published studies comparing the efficacy of IVT [12], but disagrees with another prospective cohort study that mentioned that despite mRS was lower in the posterior circulation, there was no significant difference between the two groups; this contradictory could be due to the limited sample size in the mentioned study [13] as they recruited only 30 posterior circulation and 198 anterior circulation.

Although we recorded 7 cases with mRS 6 among ACS group compared to none among PCS group, but this difference was non-significant ( $p$ value 0.61 ) which is found to be in line with other studies that reported lower mortality rate among PCS compared to ACS with lack of significant difference [13, 14].
The mean initial NIHSS was higher in ACS (10.5\%) compared to PCS (7.7\%), which matches other comparative studies as the study conducted by Libman et al. at 2001 showed mean NIHSS 9.1 and 6.5 respectively and other conducted in 2015 with mean NIHSS in the two groups 10 and 8 respectively; this could be explained by the fact that most of the NIHSS items involve the symptoms of the anterior circulation affection while symptoms of posterior circulation affection are either minimally presented, as cerebellar ataxia and visual field are not involved as vertigo, hearing loss, and other types of ataxia $[9,15]$.

Moreover, upon assessing the most common cause for morbidity and mortality in IVT patients, intracranial hemorrhage (ICH), it was found that $11 \%$ of the cases developed $\mathrm{ICH}$, which is considered higher than the incidence identified worldwide in multiple studies as NINDS trial (6.4\%) and a meta-analysis performed by Graham and Glenn in 2003 (6\%), but it is lower value than that announced in ECASS III trial (27\%) which could be explained by the difference in sample size between the two studies $[5,16,17]$.

\section{Conclusion}

Our study showed that the relative frequency of PCS is around $20 \%$ and that the outcome as regards the NIHSS showed comparable results; the functional outcome was in favor to the posterior circulation group, with lower- 
though of non-statistically significant difference-death and hemorrhagic transformation rates.

The strengths in this study is that it was performed in a tertiary center of care over 3 years, with the limitations being the small sample size as regards the posterior circulation group, the loss of cases to follow up, and the use of NIHSS with its known limitations as regards the posterior circulation despite being the standardized tool currently used and available.

\section{Abbreviations}

IVT: Intravenous thrombolysis; ACS: Anterior circulation stroke; PCS: Posterior circulation stroke; ASUH: Ain Shams University hospital; NIHSS: National institute of heath stroke scale; mRS: Modified Rankin Scale; ICH: Intracranial hemorrhage; AIS: Acute ischemic stroke; NINDS: National Institute of Neurological Disorders and Stroke; r-tPA: Recombinant tissue-type plasminogen activator; ATLANTIS: Anti-Thrombotic Strategy After Trans-Aortic Valve Implantation for Aortic Stenosis; SPSS: Statistical package for Social Science; ASUSH: Ain Shams University specialized hospital

\section{Acknowledgements}

Not applicable

\section{Declarations}

\section{Authors' contributions}

All authors have agreed to conditions noted on the Authorship Agreement Form and have read and approved the final manuscript version submitted. NT: sample collection, drafting the manuscript and analysis of data. HE: contribution in writing and reviewing the manuscript. MA: design and conceptualization of the study, reviewing the manuscript. TR: conception of the work, design, and conceptualization of the study, reviewing the manuscript.

\section{Funding}

No funding source to be declared.

\section{Availability of data and materials}

Not applicable

\section{Ethics approval and consent to participate}

Not applicable

\section{Consent for publication}

Not applicable

\section{Competing interests}

No conflict of interest to be declared.

Received: 26 January 2021 Accepted: 20 May 2021

Published online: 13 June 2021

\section{References}

1. Jauch EC, Saver JL, Adams HP Jr, Bruno A, Connors JJ, Demaerschalk BM, et al. Guidelines for the early management of patients with acute ischemic stroke: a guideline for healthcare professionals from the American Heart Association/American Stroke Association. Stroke. 2013;44(3):870-947. https:// doi.org/10.1161/STR.0b013e318284056a.

2. National Institute of Neurological Disorders and Stroke rt-PA Stroke Study Group. Tissue plasminogen activator for acute ischemic stroke. N Engl J Med. 1995;333(24):1581-7. https://doi.org/10.1056/NEJM199512143332401.

3. Schneck MJ. Current stroke scales may be partly responsible for worse outcomes in posterior circulation stroke. Stroke. 2018;49(11):2565-6. https:// doi.org/10.1161/STROKEAHA.118.023201.

4. Odier C, Michel P. Common stroke syndromes. In: Brainin M, Heiss W, editors. Textbook of Stroke Medicine. Cambridge: Cambridge University Press; 2014. p. 155-68. https://doi.org/10.1017/CBO9781107239340.010.
5. Hacke W, Kaste M, Bluhmki E, Brozman M, Dávalos A, Guidetti D, et al. Thrombolysis with alteplase 3 to 4.5 hours after acute ischemic stroke. N Engl J Med. 2008;359(13):1317-29. https://doi.org/10.1056/NEJMoa0804656.

6. Albers GW, Clark WM, Madden KP, Hamilton SA. ATLANTIS Trial. Stroke. 2002; 33(2):493-6. https://doi.org/10.1161/hs0202.102599.

7. Elsayed MA, Salah H, Sabbah A, Hatem G, Moawad MK. Early functional outcome after IV rTPA administration in Egyptian acute ischemic stroke patients. Egypt J Neurol Psychiat Neurosurg. 2019;55(1):64. https://doi.org/1 0.1186/s41983-019-0110-y.

8. Mohamed N, Nemr A, Elghareeb H, Abed E. Intravenous thrombolysis with rt-PA in patients with acute ischemic stroke: experience of Al-Azhar University Hospitals and Almaadi Military Hospital Stroke Units. Egypt J of Hospit Med. 2018;73(4):6412-6. https://doi.org/10.12816/ejhm.2018.15102.

9. Libman RB, Kwiatkowski TG, Hansen MD, Clarke WR, Woolson RF, Adams HP. Differences between anterior and posterior circulation stroke in TOAST. Cerebrovasc Dis. 2001;11(4):311-6. https://doi.org/10.1159/000047659.

10. Li H, Wong KS, Kay R. Relationship between the Oxfordshire Community Stroke Project classification and vascular abnormalities in patients with predominantly intracranial atherosclerosis. J Neurol Sci. 2003;207(1-2):65-9. https://doi.org/10.1016/s0022-510x(02)00397-0.

11. Markus HS, van der Worp HB, Rothwell PM. Posterior circulation ischaemic stroke and transient ischaemic attack: diagnosis, investigation, and secondary prevention. Lancet Neurol. 2013;12(10):989-98. https://doi.org/1 0.1016/S1474-4422(13)70211-4.

12. Förster A, Gass A, Kern R, Griebe M, Hennerici MG, Szabo K. Thrombolysis in posterior circulation stroke: stroke subtypes and patterns, complications and outcome. Cerebrovasc Dis. 2011;32(4):349-53. https://doi.org/10.1159/00033 0346.

13. Dorňák T, Král M, Šaňák D, Kaňovský P. Intravenous thrombolysis in posterior circulation stroke. Front Neurol. 2019;10:417. https://doi.org/10.3389/fneur.2 019.00417.

14. Sarikaya H, Arnold M, Engelter ST, Lyrer PA, Mattle HP, Georgiadis D, et al. Outcomes of intravenous thrombolysis in posterior versus anterior circulation stroke. Stroke. 2011;42(9):2498-502. https://doi.org/10.1161/ STROKEAHA.110.607614.

15. Dorňák T, Král M, Hazlinger M, Herzig R, Veverka T, Buřval S, et al. Posterior vs. anterior circulation infarction: demography, outcomes, and frequency of hemorrhage after thrombolysis. Int J Stroke. 2015;10(8):1224-8. https://doi. org/10.1111/ijs.12626.

16. The NINDS t-PA Stroke Study Group. Intracerebral hemorrhage after intravenous t-PA therapy for ischemic stroke. Stroke. 1997;28:2109-18. https://doi.org/10.1161/01.str.28.11.2109.

17. Graham GD. Tissue plasminogen activator for acute ischemic stroke in clinical practice. Stroke. 2003;34(12):2847-50. https://doi.org/10.1161/01.STR. 0000101752.23813.C3.

\section{Publisher's Note}

Springer Nature remains neutral with regard to jurisdictional claims in published maps and institutional affiliations.

\section{Submit your manuscript to a SpringerOpen ${ }^{\circ}$ journal and benefit from:}

- Convenient online submission

- Rigorous peer review

- Open access: articles freely available online

- High visibility within the field

- Retaining the copyright to your article

Submit your next manuscript at $\boldsymbol{\nabla}$ springeropen.com 